\section{(2) OPEN ACCESS}

\title{
Plant-based dietary approach to stage 3 chronic kidney disease with hyperphosphataemia
}

\author{
Thomas M Campbell 지, ${ }^{1}$ Scott E Liebman ${ }^{2}$
}

${ }^{1}$ Family Medicine, University of Rochester Medical Center, Rochester, New York, USA ${ }^{2}$ Nephrology, University of Rochester Medical Center, Rochester, New York, USA

Correspondence to Dr Thomas M Campbell; thomas_campbell@urmc. rochester.edu

Accepted 11 December 2019

\section{Check for updates}

(c) BMJ Publishing Group Limited 2019. Re-use permitted under CC BY-NC. No commercial re-use. See rights and permissions. Published by BMJ.

To cite: Campbell TM, Liebman SE. BMJ Case Rep 2019;12:e232080. doi:10.1136/bcr-2019232080

\section{SUMMARY}

A 69-year-old man with type 2 diabetes, hypertension and stage 3 chronic kidney disease (CKD), hyperphosphataemia and borderline hyperkalaemia presented to an office visit interested in changing his diet to improve his medical conditions. He adopted a strict whole-foods, plant-based diet, without calorie or portion restriction or mandated exercise, and rapidly reduced his insulin requirements by $>50 \%$, and subsequently saw improvements in weight, blood pressure and cholesterol. His estimated glomerular filtration rate (eGFR) increased from 45 to $74 \mathrm{~mL} / \mathrm{min}$ after 4.5 months on the diet and his microalbumin/creatinine ratio decreased from 414.3 to $26.8 \mathrm{mg} / \mathrm{g}$. His phosphorus level returned to the normal range. For individuals with CKD, especially those with obesity, hypertension, or diabetes, a strict, ad libitum whole-food, plant-based diet may confer significant benefit, although one must consider potential limitations of a creatinine-based GFR equation in the face of significant weight loss.

\section{BACKGROUND}

Approximately one in seven American adults have chronic kidney disease (CKD) and the prevalence is higher in those with metabolic risk factors such as hypertension and diabetes. ${ }^{1}$ Obesity is an independent, causative factor in CKD pathogenesis. ${ }^{2}{ }^{3}$ People with CKD have significantly higher risks of cardiovascular disease (CVD) than those without CKD. ${ }^{4}$

Given that nutrition plays an important role in metabolic health, some kidney-related organisations advise dietary approaches for CKD addressing these risk factors, ${ }^{5} 6$ including the Dietary Approaches to Stop Hypertension (DASH) diet, as it leads to weight loss, reduced blood pressure and improved glycaemic control in different populations. ${ }^{7}$ The dietary recommendations in the Kidney Disease Improving Global Outcomes focus on protein and salt intake and education with attention to potassium, salt, phosphate and protein intake, but do not make specific recommendation as to dietary patterns or specific foods. ${ }^{8}$

A more stringent whole-foods, plant-based diet (WFPBD) has been shown, over a variety of trials, to successfully treat coronary artery disease, ${ }^{9-11}$ hypertension, ${ }^{12}{ }^{13}$ obesity $^{14}$ and diabetes. ${ }^{15} 16$ Thus it is possible that a more stringent nutritional approach may yield significant benefit in patients with CKD. Unfortunately, there is limited intervention research on the effects of this dietary pattern on CKD. This case highlights the potentially remarkable benefit that a strict WFPBD may offer, particularly when used in the context of advanced metabolic disease and CKD.

\section{CASE PRESENTATION}

A 69-year-old man presented for advice regarding diet and lifestyle approaches to treat his chronic medical problems. His medical history included stage 3 CKD, class 2 obesity, hypertension, hyperlipidaemia and type 2 diabetes requiring approximately 210 total units of insulin daily (140 units insulin glargine and approximately 20-25 units insulin lispro at three meals daily).

He was most concerned about the general worsening of his numerous chronic medical conditions. His diabetes had been diagnosed roughly 30 years ago and he had progressed to requiring insulin about 4-5 years prior to our visit. His diabetes was only marginally controlled (haemoglobin A1c $7.3 \%$ ) despite steady escalation of insulin dosing and significant diet and lifestyle efforts. He was on 12 different medications (box 1) and had experienced troublesome side effects, particularly weight gain. His 'tipping point' was his recent diagnosis of hyperphosphataemia (phosphorus $4.8 \mathrm{mg} / \mathrm{dL}$ ) and a conversation with his nephrologist in which he was told that he might progress to the need for dialysis in as soon as 5 years.

He was married with a supportive wife who did the shopping and cooking. He was a retired business executive who continued to work part time on rental properties he owned. He was a former smoker (quit almost 20 years prior to visit), drank 2-3 alcoholic drinks weekly and denied illicit drug use. Foods and meals typical of his baseline diet included: a breakfast of shredded wheat, coffee, lunch of macaroni with meat sauce or grilled cheese sandwich, dinner of Italian wedding soup (with meatballs) and beans and rice. Beverages consisted of coffee, water and an occasional alcoholic drink. $\mathrm{He}$ and his wife dined out once a week. He often had an evening snack of cookies or peanut butter cheese crackers. He walked $45 \mathrm{~min}$ a day on his indoor treadmill.

\section{INVESTIGATIONS}

His laboratory values from approximately 6 weeks prior to his office visit are shown in the first column of table 1 . The estimated glomerular filtration rate (eGFR) was calculated by the Chronic Kidney Disease Epidemiology (CKD-EPI) equation, 


\section{Box 1 Baseline medications}

Amlodipine $2.5 \mathrm{mg}$ daily.

Aspirin $81 \mathrm{mg}$ daily.

Carvedilol $25 \mathrm{mg}$ two times per day.

Hydrochlorothiazide $12.5 \mathrm{mg}$ daily.

Losartan $100 \mathrm{mg}$ daily.

Pravastatin $40 \mathrm{mg}$ daily.

Insulin glargine 140 units nightly.

Insulin lispro 20-25 units three times per day before meals.

Glimepiride 4 mg daily.

Sitagliptin $100 \mathrm{mg}$ daily.

Fish oil $1000 \mathrm{mg}$ daily.

Vitamin D 2000 IU daily.

Continuous positive airway pressure device at night.

incorporating age, serum creatinine, sex and race as independent variables. ${ }^{17}$

\section{TREATMENT}

The patient and his wife were given a food guide detailing what groups of food were appropriate for a WFPBD (table 2). He was counselled to eat whenever hungry and as much as needed to be comfortably full without counting calories, carbohydrates, or restricting portion sizes. He was provided with a shopping list consisting of common products in area grocery stores consistent with the food guide and a restaurant guide to facilitate compliance with the diet while eating out. He also received a book with over 50 whole-food, plant-based recipes and 'how-to' instructions for implementing the diet. He was asked to start a vitamin B12 supplement.

The comprehensive counselling and behavioural intervention took over 1 hour and both the patient and his wife participated. They decided to start the dietary programme 3 days after the office visit.

An example day on this plan included breakfast of oatmeal with fruit and flaxseed, lunch of beans and kale (greens and beans) cooked in vegetable stock, dinner of whole-wheat spaghetti and steamed veggies, all cooked and prepared without oil, and at least two fresh clementines as snacks.

Due to the rapid effect of major dietary change on insulin sensitivity, immediate adjustments in insulin dosing were made and the patient was called daily after starting the diet to assess blood sugars and further decrease insulin as necessary.

\section{OUTCOME AND FOLLOW-UP}

The patient and his wife reported being highly compliant. They admitted to one meal a week at a restaurant when they were not $100 \%$ compliant, but otherwise followed the food guide strictly. Within 4 days, insulin had been reduced from roughly 210 to 70 units daily and glimepiride was stopped due to rapidly improving blood sugar. After his blood sugar stabilised his insulin was titrated up slightly to about 80 units a day by the end of his second week on the diet to achieve tighter glucose control.

He stopped carvedilol, hydrochlorothiazide, amlodipine and sitagliptin within the first 2 months due to improving blood pressure and blood glucose. His insulin was steadily titrated downward. His pravastatin dose was cut in half and he had a follow-up visit with nephrology about 4.5 months into the dietary change, at which point he had lost roughly $22.2 \mathrm{~kg}$. Due to marginal hyperkalaemia (potassium of $5.3 \mathrm{mmol} / \mathrm{L}$ ) and improvements in weight, blood pressure and creatinine, his nephrologist halved his losartan dose, from $100 \mathrm{mg}$ to $50 \mathrm{mg}$ daily. His insulin dose had dropped to 46 units daily total within 5 months. His remaining medications after 20 weeks of dietary change are shown in box 2 .

His renal function, as measured by creatinine and eGFR, showed slight improvement within 2 months, and significant improvement 4.5 months after changing his diet (figure 1). His creatinine was in the normal range for the first time in at least 8 years (the duration of available laboratory tests in the electronic medical record). His microalbuminuria resolved, at least temporarily, but then increased thereafter. His metabolic acidosis resolved. Selected laboratory results are shown in table 1.

Table 1 Selected laboratory values and weight before and after dietary therapy

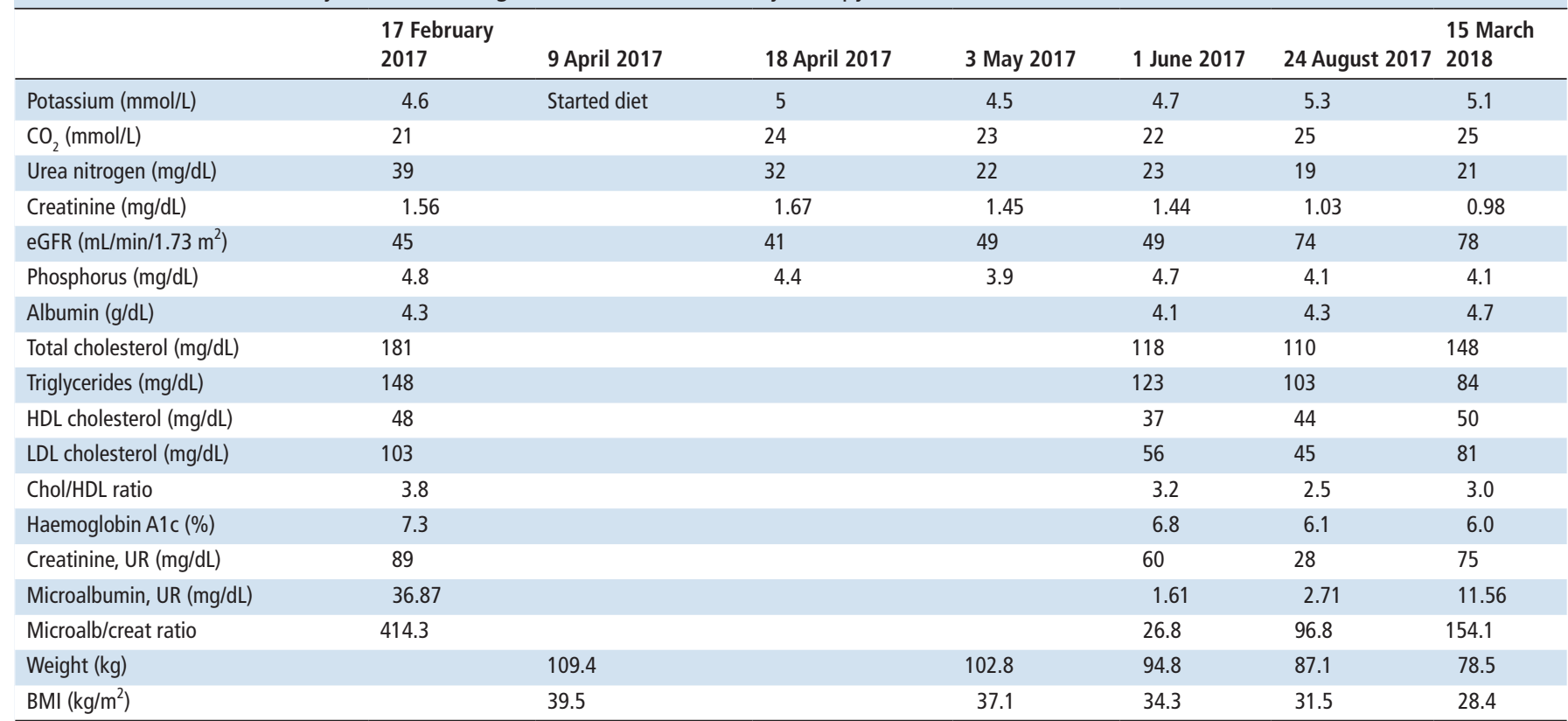

BMI, body mass index; eGFR, estimated glomerular filtration rate; HDL, high-density lipoprotein; LDL, low-density lipoprotein. 
Table 2 Food guide

\begin{tabular}{|c|c|c|}
\hline 'Allowed' foods & Foods to avoid & Foods to enjoy sparingly \\
\hline Non-starchy vegetables & Meat (including fish and poultry) & Unsalted, raw or dry roasted nuts, natural nut butters \\
\hline Starchy vegetables (potatoes and beans) & Dairy foods & Avocadoes \\
\hline Whole grains, including whole grain flours & Added pure fats (all oils, butter, margarine) & Coconut \\
\hline Fresh fruit (not dried, no juices or smoothies) & Eggs & Seeds \\
\hline All spices & Vegan 'replacement' foods_fake meats, fake cheeses & Dried fruit \\
\hline Ground flaxseed and chia seed & Refined flours & $\begin{array}{l}\text { Added sweeteners (maple syrup, fruit juice concentrate, } \\
\text { added sugars) }\end{array}$ \\
\hline \multirow[t]{2}{*}{ Water, non-dairy plant-'milks', tea } & $\begin{array}{l}\text { Predominantly 'added sugar' foods (candy, snack/energy } \\
\text { bars, cookies, cakes, pastries) }\end{array}$ & Coffee, alcohol \\
\hline & $\begin{array}{l}\text { Soda, fruit juice, sports drinks, energy drinks, blended coffee } \\
\text { and tea drinks }\end{array}$ & Refined soy protein and wheat protein (tofu, seitan) \\
\hline
\end{tabular}

His hyperphosphataemia improved on a WFPBD, without adjustment for phosphorus intake and his potassium, which had been on the high end of the normal laboratory range, remained there or marginally above the normal range. He was advised continued adherence to the food guide, but to choose lower potassium plant-based foods.

The patient and his spouse remained compliant and results from approximately 11 months after starting the diet showed persistent benefit, although his microalbuminuria increased after a nadir 4 months after changing his diet.

\section{DISCUSSION}

This case illustrates an alternative treatment approach that may be appropriate for select, highly motivated patients, using a strict WFPBD. This approach may offer effective treatment of CKD in patients with the common metabolic comorbidities of obesity, hypertension and diabetes.

Previous studies offer support for this approach, though to our knowledge few controlled diet or lifestyle intervention have shown improvement of kidney function to the degree found in this case. Goldner described two patients with lupus nephritis who improved dramatically after adoption of a raw vegan nutrition protocol. ${ }^{18}$ Banerjee et al found that among American adults with CKD, those with the highest dietary acid load (DAL) (associated with increased meat and cheese intake and reduced fruit and vegetable intake), ${ }^{19}$ had significantly higher risk of progressing to end stage renal disease (relative hazard of 3.04 for highest tertile of DAL compared with lowest tertile of DAL). ${ }^{20}$ A prospective cohort study by Khatri et $a l^{21}$ found increasing adherence to the Mediterranean diet among New Yorkers was associated with reduced risk of incident eGFR $<60 \mathrm{~mL} / \mathrm{min}$. Similarly, a randomised controlled trial found that adding fruits and vegetables to the diet of individuals with stage $3 \mathrm{CKD}$ and metabolic acidosis

\section{Box 2 Follow-up medications 30 August 2017}

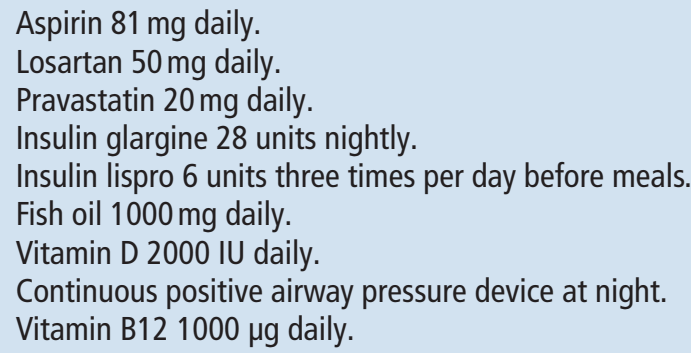

reduced blood pressure, improved the acidosis and slowed eGFR declines over 3 years compared with control patients. ${ }^{22}$ More recently Kim et al analysed data from the Atherosclerosis Risk in Communities study and found higher adherence to a healthy plant based diet correlated with a decrease rate of incident CKD. ${ }^{23}$ Apart from kidney-specific outcomes, overall mortality is significantly lower among individuals with eGFR $<60 \mathrm{~mL} / \mathrm{min}$ who consume higher ratio of plant to animal protein. $^{2425}$ This last point deserves emphasis as individuals with CKD of any stage are more likely to die prematurely than progress to dialysis, ${ }^{26}$ with CVD being the most common cause of death. ${ }^{27}$ Given the benefits of a WFPBD in CVD in general $^{9-11}$ it is feasible they exert a similar effect in CKD patients, who are already at increased CVD risk.

Phosphorus and potassium are often a concern in CKD patients. Plant-based diets may offer benefit for hyperphosphataemia as phosphorus is not as efficiently absorbed from plant sources. ${ }^{28}$ Moe et al demonstrated this in a randomised crossover trial examining nine patients randomised to alternate between an animal-protein-heavy diet or a plant-protein-heavy-diet for two separate 7-day period separated by a 2-4-week washout period. Despite the diets having a similar phosphorous content, patients' phosphorus values were significantly lower after the high plant-protein diet compared with the high animal-protein diet. ${ }^{29}$ Potassium is plentiful in plant-based diets, and the risk of hyperkalaemia requires specific dietary counselling on a case by case basis, although a small pilot study investigating the effects of 2 weeks of a DASH diet in subjects with stage 3 CKD did not find any increased risk of hyperkalaemia with the higher potassium DASH diet. ${ }^{30}$

Weight loss alone has significant impact on labs related to kidney function. Whether through bariatric surgery or pharmaceutical intervention, weight loss has been shown to improve GFR and reduce albuminuria in several studies. ${ }^{31}{ }^{32}$ Yet there are

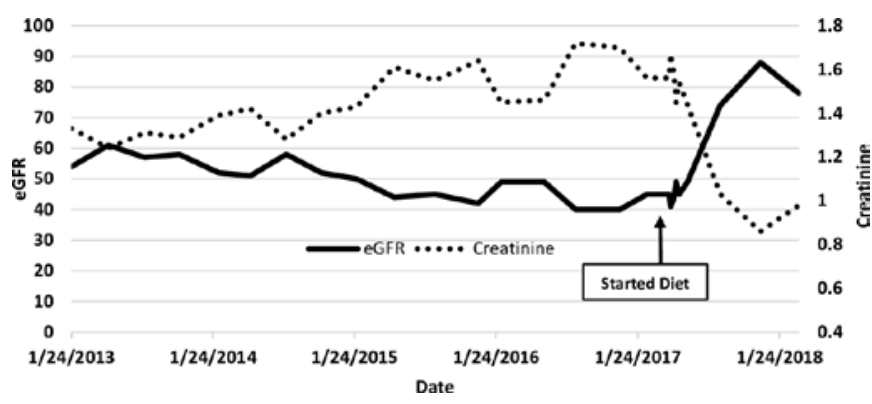

Figure 1 Changes in eGFR and creatinine from 2013 to 2018. eGFR, estimated glomerular filtration rate. 
inaccuracies in evaluating kidney function in the face of significant weight loss using creatinine-based eGFR formulas such as the CKD-EPI formula. The amount of lean body mass is significantly, positively associated with serum and urinary creatinine ${ }^{33}$ and significant weight loss is accompanied by lean body mass loss. Approximately $25 \%$ of total body weight lost, on average, may be lost from fat free mass, though this proportion is highly variable and dependent on many factors. ${ }^{34}$ Thus, serum creatinine may not be a reliable marker of kidney function in the face of significant weight loss.

In this case, while the patient dramatically improved his health in obvious, measurable ways, it is not possible to quantify exactly how much his kidney function changed given his significant weight loss $(22.2 \mathrm{~kg}$ in the first 4.5 months). Body composition was not measured in this case. One study of bariatric surgery patients without CKD found that creatininebased eGFR increased by 12\%-15\% with an average weight loss of $27 \mathrm{~kg}$, while measured GFR did not change. ${ }^{35}$ In the case presented here there was an increase in eGFR of $73 \%$, suggesting that the improvement in estimated kidney function was greater than what would be expected from weight loss alone.

\section{Patient's perspective}

At the outset, it seemed like this was going to be a difficult and restrictive way to eat. What I quickly discovered was that I could begin eating foods that I'd been depriving myself of for years because I thought they were unhealthy. By enjoying fresh, ripe fruits, for example, I was suddenly encouraged rather than discouraged. I began feeling different almost immediately and we had to decrease my insulin after ONE day. It seemed like almost overnight I had more energy than I'd had in years. Weight that I had been trying to lose for a decade began dropping off. As the weight came off, I felt lighter, and more able to move my body again. I began walking daily and am now up to 6 miles per day. This lifestyle change has been the greatest gift I've ever received. I am off most of my medications, I've lost over 70 pounds, and I've regained control over my health. I feel empowered by this lifestyle change and I finally feel like I'm in charge of my health, not just an unlucky victim shuffling from one specialist to the next. My only regret was that I didn't know about this sooner.

\section{Learning points}

- A strict whole-food, plant-based diet, excluding meat, dairy, added fats and processed foods, may offer significant benefit for a motivated patient with chronic kidney disease due to diabetes, hypertension and obesity.

- If a motivated patient makes a major dietary change to a whole-food, plant-based diet and is on high-risk medications like insulin or, to a lesser extent sulfonylureas and antihypertensives, close monitoring is required to decrease medications in advance of potential adverse effects.

- Plant-based diets may offer benefit for patients with hyperphosphataemia, as phosphorus is less readily absorbed than animal-based sources of phosphorus.

- Significant weight loss, which usually involves some degree of lean body mass loss, can reduce serum creatinine independent of its effect on renal function.
Twitter Thomas M Campbell @DrTomCampbell

Contributors TMC conducted all clinical care and wrote the original draft of the manuscript. SEL edited and revised the manuscript.

Funding The authors have not declared a specific grant for this research from any funding agency in the public, commercial or not-for-profit sectors.

Competing interests TMC receives royalties from general interest books published about nutrition and health. He also has received honoraria and travel reimbursement for general interest lectures on the topic of plant-based nutrition and health. He has received research support from the Highland Hospital Foundation, which has received donations from the T Colin Campbell Center for Nutrition Studies, the Thomas Hormel Foundation and numerous individuals.

\section{Patient consent for publication Obtained.}

Provenance and peer review Not commissioned; externally peer reviewed.

Open access This is an open access article distributed in accordance with the Creative Commons Attribution Non Commercial (CC BY-NC 4.0) license, which permits others to distribute, remix, adapt, build upon this work non-commercially, and license their derivative works on different terms, provided the original work is properly cited and the use is non-commercial. See: http://creativecommons.org/ licenses/by-nc/4.0/.

\section{ORCID iD}

Thomas M Campbell http://orcid.org/0000-0003-4449-8229

\section{REFERENCES}

1 CDC: Centers for Disease Control and Prevention. Chronic Kidney Disease (CKD) Surveillance System - United States. Available: https://nccd.cdc.gov/CKD/default. aspx

2 Kovesdy CP, Furth SL, Zoccali C, et al. Obesity and kidney disease: hidden consequences of the epidemic. J Ren Nutr 2017;27:75-7.

3 Nehus E. Obesity and chronic kidney disease. Curr Opin Pediatr 2018;30:241-6.

4 Gansevoort RT, Correa-Rotter R, Hemmelgarn BR, et al. Chronic kidney disease and cardiovascular risk: epidemiology, mechanisms, and prevention. The Lancet 2013:382:339-52.

5 National Institute of Diabetes and Digestive and Kidney Diseases. Eating right for chronic kidney disease. NIH, 2016.

6 National Kidney Foundation. Nutrition and kidney disease, stages 1-4. Available: https://www.kidney.org/nutrition/Kidney-Disease-Stages-1-4

7 Campbell AP. Dash eating plan: an eating pattern for diabetes management. Diabetes Spectr 2017:30:76-81.

8 Kidney Disease: Improving Global Outcomes (KDIGO) CKD Work Group. KDIGO 2012 clinical practice guideline for the evaluation and management of chronic kidney disease. Kidney inter Supp/ 2013;3:1-150.

9 Ornish D, Scherwitz LW, Billings JH, et al. Intensive lifestyle changes for reversal of coronary heart disease. JAMA 1998;280:2001-7.

10 Esselstyn CB, Gendy G, Doyle J, et al. A way to reverse CAD? J Fam Pract 2014:63:356-64.

11 Esselstyn CB. Updating a 12-year experience with arrest and reversal therapy for coronary heart disease (an overdue requiem for palliative cardiology). Am J Cardiol 1999;84:339-41.

12 Lindahl $\mathrm{O}$, Lindwall L, Spångberg $A$, et al. A vegan regimen with reduced medication in the treatment of hypertension. Br J Nutr 1984;52:11-20.

13 McDougall J, Litzau K, Haver E, et al. Rapid reduction of serum cholesterol and blood pressure by a twelve-day, very low fat, strictly vegetarian diet. J Am Coll Nutr 1995; 14:491-6.

14 Wright N, Wilson L, Smith M, et al. The broad study: a randomised controlled trial using a whole food plant-based diet in the community for obesity, ischaemic heart disease or diabetes. Nutr Diabetes 2017;7:e256.

15 Barnard ND, Cohen J, Jenkins DJA, et al. A low-fat vegan diet and a conventional diabetes diet in the treatment of type 2 diabetes: a randomized, controlled, 74-wk clinical trial. Am J Clin Nutr 2009;89:1588S-96.

16 Barnard RJ, Massey MR, Cherny S, et al. Long-Term use of a high-complexcarbohydrate, high-fiber, low-fat diet and exercise in the treatment of NIDDM patients. Diabetes Care 1983;6:268-73.

17 Levey AS, Stevens LA, Schmid CH, et al. A new equation to estimate glomerular filtration rate. Ann Intern Med 2009;150:604-12

18 Goldner B. Six-Week raw, vegan nutrition protocol rapidly reverses lupus nephritis: a case series. International Journal of Disease Reversal and Prevention 2019;1:11-21.

19 Remer T, Manz F. Potential renal acid load of foods and its influence on urine pH. J Am Diet Assoc 1995;95:791-7.

20 Banerjee T, Crews DC, Wesson DE, et al. High dietary acid load predicts ESRD among adults with CKD. JASN 2015:26:1693-700.

21 Khatri M, Moon YP, Scarmeas N, et al. The association between a MediterraneanStyle diet and kidney function in the Northern Manhattan study cohort. CJASN 2014;9:1868-75 
22 Goraya N, Simoni J, Jo C-H, et al. Treatment of metabolic acidosis in patients with stage 3 chronic kidney disease with fruits and vegetables or oral bicarbonate reduces urine angiotensinogen and preserves glomerular filtration rate. Kidney Int 2014;86:1031-8.

$23 \mathrm{Kim} \mathrm{H}$, Caulfield LE, Garcia-Larsen V, et al. Plant-Based diets and incident CKD and kidney function. CJASN 2019;14:682-91.

24 Chen X, Wei G, Jalili T, et al. The associations of plant protein intake with all-cause mortality in CKD. Am J Kidney Dis 2016;67:423-30.

25 Kelly JT, Palmer SC, Wai SN, et al. Healthy dietary patterns and risk of mortality and ESRD in CKD: a meta-analysis of cohort studies. CJASN 2017;12:272-9.

26 Keith DS, Nichols GA, Gullion CM, et al. Longitudinal follow-up and outcomes among a population with chronic kidney disease in a large managed care organization. Arch Intern Med 2004;164:659-63.

27 Go AS, Chertow GM, Fan D, et al. Chronic kidney disease and the risks of death, cardiovascular events, and hospitalization. N Engl J Med 2004:351:1296-305.

28 Clegg DJ, Hill Gallant KM. Plant-Based diets in CKD. CJASN 2019;14:141-3.
29 Moe SM, Zidehsarai MP, Chambers MA, et al. Vegetarian compared with meat dietary protein source and phosphorus homeostasis in chronic kidney disease. CJASN 2011;6:257-64.

30 Tyson CC, Lin P-H, Corsino L, et al. Short-Term effects of the DASH diet in adults with moderate chronic kidney disease: a pilot feeding study. Clin Kidney J 2016;9:592-8.

31 Bolignano D, Zoccali C. Effects of weight loss on renal function in obese CKD patients: a systematic review. Nephrol Dial Transplant 2013;28:iv82-98.

32 Imam TH, Fischer $\mathrm{H}$, Jing $\mathrm{B}$, et al. Estimated GFR before and after bariatric surgery in CKD. American Journal of Kidney Diseases 2017;69:380-8.

33 Baxmann AC, Ahmed MS, Marques NC, et al. Influence of muscle mass and physical activity on serum and urinary creatinine and serum cystatin C. CJASN 2008;3:348-54.

34 Heymsfield SB, Gonzalez MCC, Shen W, et al. Weight loss composition is one-fourth fat-free mass: a critical review and critique of this widely cited rule. Obes Rev 2014;15:310-21.

35 von Scholten BJ, Persson F, Svane MS, et al. Effect of large weight reductions on measured and estimated kidney function. BMC Nephrol 2017;18:52.

Copyright 2019 BMJ Publishing Group. All rights reserved. For permission to reuse any of this content visit https://www.bmj.com/company/products-services/rights-and-licensing/permissions/

BMJ Case Report Fellows may re-use this article for personal use and teaching without any further permission.

Become a Fellow of BMJ Case Reports today and you can:

- Submit as many cases as you like

Enjoy fast sympathetic peer review and rapid publication of accepted articles

- Access all the published articles

Re-use any of the published material for personal use and teaching without further permission

\section{Customer Service}

If you have any further queries about your subscription, please contact our customer services team on +44 (0) 2071111105 or via email at support@bmj.com.

Visit casereports.bmj.com for more articles like this and to become a Fellow 